\title{
Exploring the Impact of Environmental Regulation and Economic Agglomeration on Ecological Efficiency in China
}

\author{
Hui Hou ${ }^{1}$, Huihui Guo ${ }^{1 *}$, Xiaofang Yun ${ }^{2}$ \\ ${ }^{1}$ School of Business Administration, Northeastern University, Shenyang, P. R. China \\ ${ }^{2}$ School of Finance and Economics, Shenyang Open University, Shenyang, P. R. China
}

Received: 7 May 2021

Accepted: 18 July 2021

\begin{abstract}
The objective of this paper was to explore the impact of environmental regulation and economic agglomeration on regional ecological efficiency in China. First, this paper adds energy factor and pollutant emission output to the production function and proves by the derivation of the mathematical model that environmental regulation and economic agglomeration can affect eco-efficiency. Second, based on the panel data of 30 province-level regions in China from 2003 to 2017, the dynamic spatial panel Durbin model and the mediating effect test model are used to empirically analyze the relationship between the three. The results show that economic agglomeration and eco-efficiency present a typical $\mathrm{N}$-shaped curve relationship. Environmental regulation can enhance eco-efficiency and economic agglomeration, and economic agglomeration can be a mediator of environmental regulation to affect eco-efficiency. The joint implementation of environmental regulation and agglomeration economic is helpful to the improvement of ecological efficiency. Both eco-efficiency and economic agglomeration have significant time dependence and spatial spillover effects. From a regional perspective, the marginal role of environmental regulation in promoting eco-efficiency in the central and western regions is greater than that in the eastern regions. The impact of economic agglomeration on eco-efficiency still shows significant $\mathrm{N}$-type characteristics in the central region, while it shows an inverted N-type characteristic in the eastern region, but it is not significant in the western region.
\end{abstract}

Keywords: environmental regulation, economic agglomeration, ecological efficiency, green economy, spatial panel Durbin model

e-mail: 1901100@stu.neu.edu.cn 


\section{Introduction}

There is no doubt that China's economy has made remarkable achievements, and its GDP currently ranks second in the world, but at the cost of serious environmental damage and shortage of energy resources [1]. From the perspective of reality, the agglomeration economy represented by urban agglomeration has become a typical feature that cannot be ignored in the process of implementing regional development strategy in China. However, while promoting economic growth through the use of various positive externalities (such as sharing, learning, and various spillover effects) of the agglomeration economy, the agglomeration and rapid expansion of industrial enterprises and population concentration have also caused environmental problems. Chinese air pollutants (mainly sulfur dioxide), as well as sewage and solid waste emissions, are currently ranked first in the world, and China has been the world's largest energy-consuming country since 2009. The Yangtze River Delta, Beijing-Tianjin-Hebei, and other urban agglomerations are not only the regions with the highest degree of agglomeration in China but also areas with frequent environmental problems [2]. Meanwhile, due to the externality of pollution and the public goods nature of the environment, it is difficult to solve the pollution problem effectively by relying solely on the market mechanism, and environmental regulation has become a better choice for the government to make up for market failure. Facing the pressure environment and resources, environmental regulation will still be an effective policy advocated by the government. And the agglomeration development model represented by urban agglomeration is also the government's efforts to promote. So environmental regulation and economic agglomeration are two key factors for China to realize the development of green economy. We hope that with the cooperation of environmental regulation while pursuing the maximization of the positive externality benefits of the spatial agglomeration of economic activities, economic entities also minimize pollution emissions and promote regional eco-efficiency. Therefore, it is of urgent and important practical significance to discuss the development of China's green economy by bringing environmental regulation, economic agglomeration, and ecological efficiency into the same analytical framework.

Ecological efficiency (eco-efficiency) considers many factors such as economy, resources, and environment, and has become an important concept and tool for measuring sustainable development and green economy development, and also provides an important theoretical basis for enterprises to achieve "win-win" environmental and economic benefits [3, 4]. Eco-efficiency was first introduced by Schaltegger and Sturm (1990), which refers to the ratio of increased economic value to increased ecological environment cost (including resource consumption and pollution emissions) over a period [5, 6]. From the macro level, scholars focus on achieving economic growth with less resource input and reducing pollutant emissions as much as possible, so eco-efficiency is essentially the input-output efficiency under the dual constraints of resources and environment. China's future pursuit of green economic development should also be a process of gradual improvement of eco-efficiency.

Economic agglomeration refers to the phenomenon that economic activities are relatively concentrated in a certain geographical area [7]. There are also different opinions on the relationship between economic agglomeration and pollution, such as positive correlation, negative correlation, non-linearity and so on [8-12]. However, there is little discussion about the impact of economic agglomeration on eco-efficiency considering economic growth and environmental pollution. Ren et al. (2019) conclude that the diversified industrial agglomeration can promote the green economy, while specialized industrial agglomeration is on the contrary [13]. Yu et al. (2018) found dynamic agglomeration externalities and eco-efficiency present an inverted U-shaped relationship through empirical study [14]. Lin and Tan (2019) found that when the degree of economic agglomeration is greater than the critical value, its impact on green economic efficiency is negative [15]. As explained above, a nonlinear or more complex relationship may exist between economic agglomeration and eco-efficiency. On the one hand, as a compact spatial economic behavior, the economic agglomeration can produce various positive externalities, which is conducive to promoting technological progress and improving factor utilization efficiency, thus showing a positive effect on eco-efficiency; on the other hand, economic agglomeration may increase energy consumption and corresponding pollutants emissions due to the rapid expansion of production scale and lagging cleaner production technology, thus having a negative effect on the improvement of eco-efficiency. Therefore, what kind of influence direction and mechanism may the economic agglomeration phenomenon in the process of China's regional economic development show on the regional eco-efficiency? This is one of the questions to be answered in this paper.

As an important measure to limit pollution emissions, the relationship between environmental regulation and eco-efficiency has been concerned by scholars. For one thing, many works of literature emphasize that the strengthening of environmental regulation increases the cost of the government and enterprises, which is not conducive to technological innovation, thereby suppressing output growth and economic development, and restricting regional eco-efficiency [16-18]. Another view from a dynamic perspective is that reasonable environmental regulation can promote technological innovation, and the environment quality and economic output can be both acquired [19-21]. Besides, some scholars have also concluded that the impact of environmental regulation on eco-efficiency is uncertain, 
which will show differences due to the existence of different forms of regulation, regional differences, and industry heterogeneity [22-24], and they all believe that environmental regulations can play a positive role in the improvement of eco-efficiency.

In the face of the strong environmental regulation of the government, polluting enterprises may be shut down, relocate or carry out the green transformation. And according to the Porter hypothesis, environmental regulation will encourage enterprises to carry out technological innovation, so as to promote the agglomeration of high-tech industries. These decisions of enterprises will directly affect the spatial distribution of economic activities and then affect economic agglomeration. Therefore, scholars also pay attention to the impact of environmental regulation on economic agglomeration. The first recognizes that economic agglomeration can be promoted by environmental regulation [25]. Andreoni and Levinson (2001) believe that enterprises will share the cost of environmental regulation in the way of agglomeration, resulting in the scale effect of environmental protection [26]. Wang et al. (2018) think higher environmental regulation can stimulate manufacturing subsectors to obtain more agglomeration economies with less carbon dioxide emissions [27]. Another conclusion drawn through empirical analysis is that the relationship between environmental regulation and economic agglomeration is not linear or single. Hao et al. (2016) found that the relationship between them will be different due to industrial category and scale, and from the overall scale of non-agricultural industries, environmental regulation and economic agglomeration show "U-shaped" characteristics [28]. Thus, it follows that some studies believe that environmental regulation and economic agglomeration are correlated, but the conclusions are divergent, so can environmental regulation affect ecoefficiency by affecting economic agglomeration? This is the second core issue concerned in this paper, but in the existing research, there is a lack of literature to analyze this transmission mechanism.

This paper mainly discusses the impact of environmental regulation and economic agglomeration on eco-efficiency in China. The marginal contribution of this paper is: Firstly, although there have been abundant studies on the relationship between environmental regulation, economic agglomeration, and eco-efficiency, they all focus on the relationship between pairs. And previous studies lack mathematical model derivation, mainly based on theoretical conjecture, and then select relevant variables for regression. This paper brings the three into the same analysis framework for the first time, and it is proved that environmental regulation and economic agglomeration can affect eco-efficiency through the derivation of mathematical model, which expands the scientific research logic of this kind of problem. Secondly, based on the panel data of 30 provincial regions in China from 2003 to 2017, this paper empirically examines the relationship among the three under robust conditions and then concludes that the $\mathrm{N}$-curve relationship exists between economic agglomeration and eco-efficiency in China. This is a new point of view, which enriches the understanding of the curvilinear relationship between economic agglomeration and eco-efficiency. Finally, it is found that environmental regulation can enhance economic agglomeration and economic agglomeration can become the mediator of environmental regulation affecting ecoefficiency. This is a transmission path for environmental regulation to affect eco-efficiency, which has been paid no attention to in previous studies. This conclusion further shows that environmental regulation and economic agglomeration can achieve the policy effect of mutual benefit, which provides a new theoretical basis and ideas for China to explore the policy-making of the green development model.

\section{Methods}

\section{Theoretical Model Derivation}

Ciccone and hall (1996) considered the influence of spatial factors on output and provided a basic theoretical analysis framework for describing spatial production activities from the perspective of the density of economic activities [29]. Based on the production density model [30], the energy factors and pollutant emission output are brought into the production function to derive the model $[31,32]$.

Assuming that a country $c$ has many regions, $q$ is the total output per unit area of region $i$. During the production process, the expected output of $Q_{c i}$ units is produced and there will be pollution emissions of $W_{c i}$ units. The production function can be expressed as:

$$
q=\left(Q_{c i}+W_{c i}\right) / A_{c i}=f\left(l, k, e, \phi, A_{c i}, Q_{c i}, W_{c i}\right)
$$

where $l, k$, and $e$ are labor, capital, and energy input per unit area of region $i$, respectively; $\phi$ is the economic output efficiency that considers capital, labor and energy input, expected output and undesired output (pollution emissions) in the production activities, that is, the ecoefficiency to be studied in this paper; $A_{c i}$ is the total land area of region $i$. The specific form of the production function is:

$$
\begin{aligned}
q & =\left(Q_{c i}+W_{c i}\right) / A_{c i}=f\left(l, k, e, \phi, A_{c i}, Q_{c i}, W_{c i}\right) \\
& =\phi_{c i}\left(l^{\beta} k^{\gamma} e^{1-\beta-\gamma}\right)^{\alpha}\left[\left(Q_{c i}+W_{c i}\right) / A_{c i}\right]^{\frac{\lambda-1}{\lambda}}
\end{aligned}
$$

where $\alpha(0 \leq \alpha \leq 1)$ is the income share of the three inputs to land. B and $\gamma$ are the output elasticity of labor and capital, respectively $(0 \leq \beta \leq 1 ; 0 \leq \gamma \leq 1)$. $(\lambda-1) / \lambda$ is the output elasticity of density, which reflects the positive externality effect of agglomeration [30]. Assume that labor, capital and energy are evenly distributed over the 
land of each region, the total output of region $i$ can be expressed as:

$$
\begin{aligned}
Q_{c i}+W_{c i} & =q A_{c i}=\phi_{c i}\left(l^{\beta} k^{\gamma} e^{1-\beta-\gamma}\right)^{\alpha}\left[\left(Q_{c i}+W_{c i}\right) / A_{c i}\right]^{\frac{\lambda-1}{\lambda}} A_{c i} \\
& =A_{c i} \phi_{c i}\left[\left(\frac{L_{c i}}{A_{c i}}\right)^{\beta}\left(\frac{K_{c i}}{A_{c i}}\right)^{\gamma}\left(\frac{E_{c i}}{A_{c i}}\right)^{1-\beta-\gamma}\right]^{\alpha}\left(\frac{Q_{c i}}{A_{c i}}\right)^{\frac{\lambda-1}{\lambda}}\left(1+\frac{W_{c i}}{Q_{c i}}\right)^{\frac{\lambda-1}{\lambda}}
\end{aligned}
$$

where $L, K$, and $E$ are the total labor, total capital, and total energy consumption required for the production process in region $i$. Assuming that factors can flow across regions, the price of factors in each region in an equilibrium state is equal. According to the principle that the marginal output of each factor of production equals the price, we can get:

$$
K_{c i}=\frac{\alpha \gamma\left(Q_{c i}+W_{c i}\right)}{r_{c}}, E_{c i}=\frac{\alpha(1-\beta-\gamma)\left(Q_{c i}+W_{c i}\right)}{p_{c}}
$$

where $r$ and $p$ refer to the price of capital and energy. Substituting (4) into (3) allows us to get:

$$
\phi_{c i}=\left(\frac{Q_{c i}}{A_{c i}}\right)^{\mu}\left(1+\frac{W_{c i}}{Q_{c i}}\right)^{\theta}\left(\frac{Q_{c i}}{L_{c i}}\right)^{\sigma} \Gamma
$$

where

$\mu=\frac{1-\alpha \lambda}{\lambda}, \theta=\frac{1-\alpha \lambda(1-\beta)}{\lambda}, \sigma=-\alpha \beta, \Gamma=\left(\frac{\alpha \gamma}{r_{c}}\right)^{-\alpha \gamma}\left(\frac{\alpha(1-\beta-\gamma)}{p_{c}}\right)^{\alpha(\beta+\gamma-1)}$, $\mu, \theta, \sigma$, and $\Gamma$ are all constants. Rewrite Equation (5) as a log-linear model to obtain:

$$
\ln \phi_{c i}=\ln \Gamma+\mu \ln \left(\frac{Q_{c i}}{A_{c i}}\right)+\theta \ln \left(1+\frac{W_{c i}}{Q_{c i}}\right)+\sigma \ln \left(\frac{Q_{c i}}{L_{c i}}\right)
$$

After performing Taylor expansion on $\ln \left(1+W_{c i} /\right.$ $\mathrm{Q}_{c i}$ ), we get: $\ln \left(1+W_{c i} / \mathrm{Q}_{c i}\right) \approx W_{c i} / \mathrm{Q}_{c i}$. Equation (6) can be rewritten as:

$$
\ln \phi_{c i}=\ln \Gamma+\mu \ln \left(\frac{Q_{c i}}{A_{c i}}\right)+\theta\left(\frac{W_{c i}}{Q_{c i}}\right)+\sigma \ln \left(\frac{Q_{c i}}{L_{c i}}\right)
$$

In Equation (7), the left side is the natural logarithm of eco-efficiency, and the right side contains the core explanatory variables that this paper focuses on: economic agglomeration $\left(Q_{c i} / A_{c j}\right)$, which is measured by the output of unit land area; environmental regulation $\left(W_{c i} / Q_{c i}\right)$ measured by the pollutant emission per unit output, and $\left(Q_{c i} / L_{c i}\right)$ is the output of unit labor force, which represents labor productivity and is one of the control variables of this paper. Equation (7) is the basis of the later empirical model, which not only proves that environmental regulation and economic agglomeration can affect ecological efficiency from the mathematical model, but also shows the rationality of bringing environmental regulation, economic agglomeration, and ecological efficiency into the same analytical framework.

\section{Empirical Model Construction}

\section{Variables}

Eco-efficiency $(E E)$ : The data envelopment analysis (DEA) is often used to estimate the resource allocation efficiency of decision-making units (DMU) [33]. Tone (2002) put forward the slack-based measure (SBM) of super-efficiency, which not only figures out the problem that the slackness of input and output can't be well appreciated in traditional CCR and BCC models, but also allows the efficiency value of DMU to exceed 1, and then distinguish the effective order of DMU based on the efficiency value (The traditional DEA model generally stays at 1 after the efficiency value reaches 1) [34]. Furthermore, the super-efficiency SBM model with non-expected can avoid the eco-efficiency deviation caused by improper treatment of non-expected output [35]. Due to the existence of technological progress and other reasons, the super-efficiency SBM model with non-expected under the condition of variable scale return (VRS) is chosen to calculate the eco-efficiency. Capital stock, labor force, and energy consumption are selected as input variables. The capital stock input is obtained using the perpetual inventory method, and the original data required is the amount of fixed capital formation in each region, with 2003 as the base period and an annual depreciation rate of $10.96 \%$ [36]. The labor input index takes the average value of the number of people employed at the end of the current year and that at the end of the previous year as the number of employees in that year. The total energy consumption of each region is used as the energy factor input. Select the GDP and per capita GDP of each region which all have been converted to constant prices in 2003 as the expected output variables. Select the current year's chemical oxygen demand, sulfur dioxide, and smoke (dust) emissions in each region as the non-expected output.

Economic agglomeration ( $L E A)$ : Ciccone and Hall (1996) proposed that the amount of economic activity carried per unit area can better scale the economic agglomeration level of an area [29]. This paper chooses the logarithm of the ratio of non-agricultural output to the urban area in each region to measure economic agglomeration [2]. The main reason for choosing urban areas is to overcome the impact of sparsely populated areas in certain areas. Meanwhile, this paper introduces the square term (SLEA) and cubic term (CLEA) of economic agglomeration level to probe into the possible nonlinear relations between economic agglomeration and eco-efficiency. If results show that the cubic term is not significant but the square term is significant, then the model can be simplified to a quadratic function. 
Environmental regulation $(E R)$ : Whether it is market-based environmental regulation or imperative environmental regulation, the ultimate effect is the reduction of pollution emissions. The environmental regulation is indicated by calculating the comprehensive index of the discharge of various pollutants per unit GDP of each region. A smaller pollutant emission index means a higher intensity of environmental regulation, and the calculation process is as follows:

1. Standardize the chemical oxygen demand, sulfur dioxide, and smoke (dust) emissions per unit GDP of each region, where PEij is the class $\mathrm{j}$ pollutant emission per unit GDP of $\mathrm{i}$ region. The maximum and minimum emission of class $\mathrm{j}$ pollutants per unit GDP in all regions are expressed as max (PEj) and $\min (\mathrm{PEj})$, and is the standardized value of the index;

$$
P E_{i j}^{s}=\left[P E_{i j}-\min \left(P E_{j}\right)\right] /\left[\max \left(P E_{j}\right)-\min \left(P E_{j}\right)\right]
$$

2. Calculate the weight of each pollutant.

$$
W_{j}=P E_{i j} / \overline{P E_{i j}}
$$

$\overline{P E_{i j}}$ is the regional average level of $j$ pollutant emission per unit GDP during the sample period.

3. Calculate the intensity of environmental regulation.

$$
E R_{i t}=1 / 3 \sum_{j=1}^{3} W_{j} P E_{i j}^{S}
$$

There are many factors that affect the change of eco-efficiency, so a group of control variables are introduced. The descriptive statistics of each variable are shown in Table 1.

Urbanization rate $(U R)$ : Using the proportion of the urban population in the total population to measure the urbanization rate. The urbanization process will generate higher energy demand and may cause a corresponding increase in pollution. Nevertheless, after the urbanization rate is over the threshold, the improvement of urban infrastructure and the application of new environmental protection technologies will all contribute to enhance eco-efficiency. Therefore, this paper introduces the urbanization rate and its square term $(S U R)$ in the model and expects that urbanization rate and eco-efficiency are a U-shaped relationship.

Industry structure $(I S)$ : The larger the proportion of industry in the industrial structure, the less conducive to the reduction of pollution emissions. Therefore, using the proportion of industrial added value to describe the impact of industrial structure on ecological efficiency, and its coefficient symbol is expected to be negative.

Degree of marketization $(M A)$ : Increased marketization will improve the efficiency of resource allocation and energy use, and then affect the ecoefficiency. Select the proportion of non-state-owned enterprise employees in total employees indicate the degree of marketization [2].

Degree of government intervention $(G R)$ : Limited government intervention in the economic market can adjust the allocation of resources and alleviate the problem of market failure, but if the government intervenes too much in the market, it will disrupt the market order, so government intervention directly affects the allocation of resources, thus affecting ecoefficiency. The degree of government intervention is measured by the proportion of local fiscal expenditure

\begin{tabular}{|c|c|c|c|c|c|c|}
\hline Variable & Obs & Mean & Std. Dev. & Min & Max & Unit \\
\hline$E E$ & 450 & 0.55 & 0.358 & 0.175 & 1.454 & - \\
\hline$E R$ & 450 & 0.261 & 0.294 & 0.00004 & 1.689 & - \\
\hline$L E A$ & 450 & -2.033 & 1.269 & -5.914 & 0.793 & 100 million yuan per square kilometer \\
\hline$U R$ & 450 & 51.489 & 14.424 & 24.77 & 89.6 & $\%$ \\
\hline$I S$ & 450 & 39.536 & 9.995 & 11.823 & 73.225 & $\%$ \\
\hline$M A$ & 450 & 24.782 & 15.39 & 4.25 & 97.935 & $\%$ \\
\hline$G R$ & 450 & 20.887 & 9.391 & 6.77 & 62.686 & $\%$ \\
\hline$S T I$ & 450 & 0.346 & 0.235 & 0.109 & 1.431 & $\%$ \\
\hline$F D$ & 450 & 1.084 & 0.612 & 0.338 & 4.623 & - \\
\hline$T E C$ & 450 & 9.416 & 14.103 & 0.236 & 86.706 & $\%$ \\
\hline IF & 450 & 89 & 37.7 & 17.4 & 22.81 & $\%$ \\
\hline$T S A$ & 450 & 0.956 & 0.611 & 0.04 & 2.94 & $\%$ \\
\hline$L P$ & 450 & 0.819 & 0.569 & -0.707 & 2.205 & 100 million yuan per ten thousand people \\
\hline
\end{tabular}
to local GDP.

Table 1. Descriptive Statistics. 
Science and technology investment (STI): Increasing investment in science and technology will help to promote technological progress and improve the production efficiency of enterprises, thus having an impact on eco-efficiency. The proportion of local government of expenditure on science and technology to GDP in each region is selected to indicate science and technology investment.

Degree of fiscal decentralization $(F D)$ : Under fiscal decentralization, in order to maximize their own interests, local governments' fiscal expenditure may focus on economic construction, but lack of financial support for environmental protection, and the competition for political achievements between them may also cause local governments to relax their environmental supervision policies, thus restraining eco-efficiency. Select the per capita fiscal expenditure in the provincial budget and the fiscal expenditure in the central budget to indicate the degree of fiscal decentralization [23].

In addition, considering the externalities of economic agglomeration, knowledge spillover, infrastructure, and labor productivity are also introduced. First, select the average number of patents granted by 10,000 people to indicate measure the knowledge spillover (TEC). Second, measure the transportation infrastructure (TSA) by dividing the operating mileage of highways and railways by 4 times the total area by the operating mileage of highways in each region [28]; use telephone penetration rate to indicate information communication infrastructure $(I F)$. Finally, the more advanced the labor market, the higher its labor productivity, which plays an important role in forming economies of scale. So, this paper uses the logarithm of non-agricultural output per labor to measure labor productivity $(L P)$.

\section{Dynamic Spatial Panel Durbin Model}

It has been proved that both economic agglomeration and eco-efficiency have spatial correlation [2, 37, 38]. Therefore, the spatial panel Durbin model (SDM) be chosen for empirical analysis. The spatial correlation may come not only from the explained variable itself, but also from the explanatory variable and error term, while the spatial Durbin model (SDM) can well reflect the spatial correlation from different sources [39]. Moreover, considering the possible time-dependent path dependence of ecological efficiency, and the endogenous problems caused by environmental regulation, economic agglomeration, and eco-efficiency that may interact with each other, the lag period of eco-efficiency is introduced at the same time, further add other control variables to construct a dynamic spatial panel Durbin model. Based on Equation (7), the empirical model is set as follows:

$$
\begin{gathered}
L E E_{i t}=\beta_{0}+\beta_{1} L E E_{i, t-1}+\rho_{0} \sum_{i=1}^{n} w_{i j} L E E_{j, t-1}+\rho_{1} \sum_{i=1}^{n} w_{i j} L E E_{j t} \\
+\beta_{2} E R_{i t}+\rho_{2} \sum_{i=1}^{n} w_{i j} E R_{j t}+\beta_{3} L E A_{i t}+\rho_{3} \sum_{i=1}^{n} w_{i j} L E A_{j t} \\
+\beta_{4} S L E A_{i t}+\rho_{4} \sum_{i=1}^{n} w_{i j} S L E A_{j t}+\beta_{5} C L E A_{i t}+\rho_{5} \sum_{i=1}^{n} w_{i j} C L E A_{j t} \\
+\delta \sum X_{i t}+\lambda \sum_{i=1}^{n} w_{i j} X_{j t}+\mu_{i}+\varepsilon_{i t}
\end{gathered}
$$

where $i$ is the region, and $t$ is the year. $X$ is control variable, $\beta$ is coefficient to be estimated, $\rho$ and $\lambda$ are spatial lag coefficients of core explanatory variable and control variable, $W_{i j}$ stands for spatial weight matrix. Without loss of generality, this article chooses the most commonly used geographic adjacency weight matrix. When the two regions are geographically adjacent, $W_{i j}=1$, when they are not geographically adjacent, $W_{i j}^{l j}=0 . M$ is the regional fixed effect, and $\varepsilon$ is the random disturbance term.

\section{Mediating Effect Test Model}

Environmental regulation may act on eco-efficiency by influencing economic agglomeration. In order to test whether economic agglomeration acts as an intermediary variable, this paper uses a standardized mediation effect test model is proposed by Baron and Kenny (1986) to conduct further empirical investigations [40]. The time lag and spatial lag terms of ecoefficiency and economic agglomeration are introduced into Equation (12) and Equation (13) respectively, as well as other control variables ${ }^{1}$, are taken as the control variables of the mediation variable model. The specific mediation effect test model is set as follows:

$$
\begin{gathered}
L E E_{i t}=\alpha_{0}+\alpha_{1} L E E_{i, t-1}+\alpha_{2} E R_{i t}+\theta_{0} \sum_{i=1}^{n} w_{i j} L E E_{j, t-1} \\
+\theta_{1} \sum_{i=1}^{n} w_{i j} L E E_{j t}+\theta_{2} \sum_{i=1}^{n} w_{i j} E R_{j t}+\phi X_{i t}+\theta \sum_{i=1}^{n} w_{i j} X_{j t}+v_{i}+\varsigma_{i t} \\
L E A_{i t}=\lambda_{0}+\lambda_{1} L E A_{i, t-1}+\lambda_{2} E R_{i t}+\eta_{0} \sum_{i=1}^{n} w_{i j} L E A_{j, t-1} \\
+\eta_{1} \sum_{i=1}^{n} w_{i j} L E A_{j t}+\eta_{2} \sum_{i=1}^{n} w_{i j} E R_{j t}+\pi X_{i t}+\eta \sum_{i=1}^{n} w_{i j} X_{j t}+v_{i}+\xi_{i t}
\end{gathered}
$$

Equation (11), (12), and (13) together constitute the mediating effect test model of economic agglomeration. Besides, Equation (13) can also be used as a test model for whether environmental regulation promote economic agglomeration.

Equation (12) includes all control variables and Equation (13) includes all control variables except the square term of urbanization. 
Table 2. Spatial correlation Test of residuals based on OLS estimation results.

\begin{tabular}{|c|c|c|c|}
\hline \multirow{2}{*}{ Variable } & Equation (11) & Equation (12) & Equation (13) \\
\cline { 2 - 4 } & LEE & LEE & $0.7943^{* * *}$ \\
\hline \multirow{2}{*}{ Moran's I } & $0.3164^{* * *}$ & $0.3232 * * *$ & {$[0.000]$} \\
\hline LM-Error & {$[0.000]$} & $70.000]$ & $472.4868^{* * *}$ \\
\hline LM-Lag & $72.2184 * * *$ & {$[0.000]$} & {$[0.000]$} \\
(robust) & {$[0.000]$} & $14.1689^{* * *}$ & -0.2 .2470 \\
\hline
\end{tabular}

Note: $* * *, * *, *$ indicate $1 \%, 5 \%$, and $10 \%$ significance, respectively. The $p$ value in square brackets.

\section{Parameter Estimation Method}

Because the time lag term of the explained variable exists in Equations (11), (12) and (13) as explanatory variables, the estimated values obtained by the traditional ordinary least squares (OLS) estimation and least squares dummy variable (LSDV) estimation are no longer consistent. To solve this problem, the generalized methods of moment (GMM) estimation are generally used, and compared with traditional spatial maximum likelihood estimation (MLE) methods, the GMM estimation method can also better control the potential endogenous problems. This paper mainly uses the HanPhillips GMM estimation method proposed by Han and Phillips (2010) to estimate the parameters [41]. The issue of weak instrumental variables in the differential GMM estimation and traditional instrumental variable method and can be better dealt with by Han-Phillips GMM estimation, and it can still get consistent and unbiased estimation results under the condition of small samples.

Besides, to judge the rationality of using the spatial panel model, the spatial correlation also is conducted. And the spatial panel model also includes fixed effect (FE) and random effect (RE) two basic setting forms, which can still be set and screened by the popular Hausman test [39].

\section{Data Sample Description}

Judging from the reality of China, the level of economic agglomeration in various regions has undergone an evolution process from low to high. At the same time, the obvious difference in economic agglomeration level presents in different areas of China. The eastern region is recognized as an area with a high degree of economic agglomeration, while the central and western regions are relatively low. The existence of this difference can enrich the diversity of data and make parameter estimation more accurate. Therefore, China is a good sample for studying economic agglomeration related issues so that the panel data of 30 provincial administrative regions of the Chinese mainland from 2003 to 2017 (Tibet was deleted because of the serious lack of data) as the research sample. Any data can be found in China Statistical Yearbook,
China Urban Construction Statistical Yearbook, China Environmental Statistical Yearbook, and provincial statistical yearbooks over the years. All value variables have been converted to constant prices in 2003. In this paper, natural logarithmic transformation is performed on non-percentage variables to control the heteroscedasticity of the model as much as possible.

\section{Results and Analysis}

\section{The Regional Difference of Eco-Efficiency in China}

Max-DEA software is used to measure the ecological efficiency of 30 provincial regions in China. The larger the value is, the closer it is to the frontier level of green production, and the higher the eco-efficiency is. From the trend of eco-efficiency of total samples and subarea ${ }^{2}$ samples from 2003 to 2017 (Fig. 1), the following two characteristics can be found. First, the average eco-efficiency of the total sample and the region decreased at first and then tended to be stable, indicating that the construction of ecological civilization in China effectively restraining the downward trend of eco-efficiency. Second, there are obvious regional differences. The eco-efficiency of eastern regions was far ahead of the national average level and inland areas and showed a trend of picking up since 2016. In the central regions, the eco-efficiency declined the most and has lagged behind the western region since 2006 . This may be caused by the inconsistency in the process of inter-regional industrialization. The development model of eastern China is relatively mature, in

\footnotetext{
With reference to the division method of the National Bureau of Statistics of China. The eastern region includes Beijing, Tianjin, Hebei, Shandong, Jiangsu, Shanghai, Zhejiang, Fujian, Guangdong, Hainan, and Liaoning. The central region includes Henan, Hubei, Hunan, Anhui, Jiangxi, Shanxi, Jilin, and Heilongjiang. The western region includes Chongqing, Sichuan, Yunnan, Guizhou, Guangxi, Shaanxi, Gansu, Ningxia, Xinjiang, Qinghai, and Inner Mongolia. http:// www.stats.gov.cn/tjsj/zxfb/201605/t20160514_1356334. html
} 


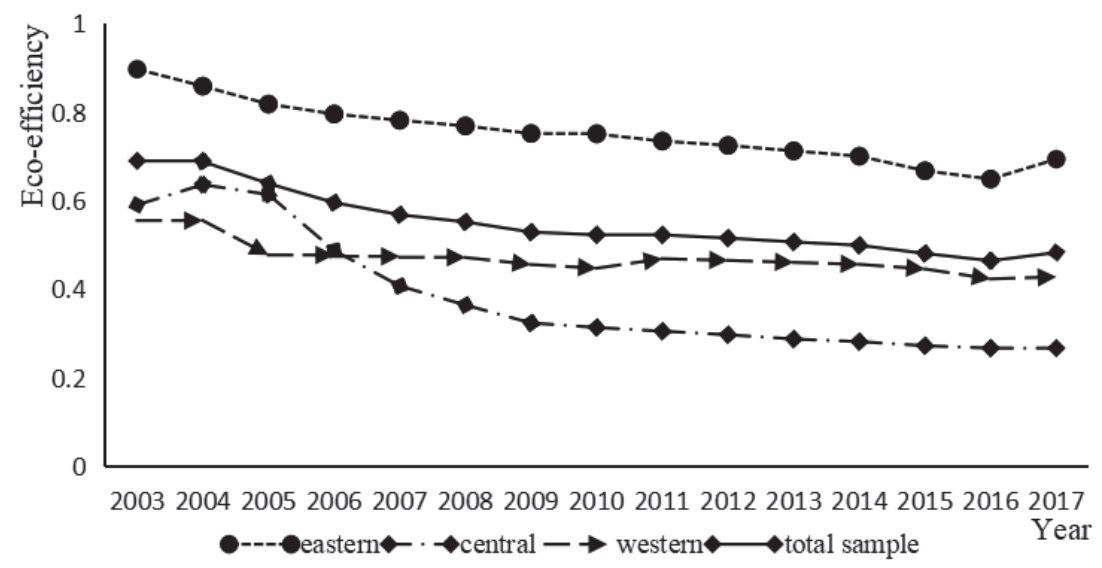

Fig.1. Mean trend of eco-efficiency in China (total sample and subarea).

the meantime, its economy and environment are showing a good momentum of coupled and coordinated development. However, a large amount of capital in the central region is concentrated in the industry, while the overall industrialization process of the western region is relatively slow.

\section{Spatial Correlation Test Results}

This paper first tests the spatial correlation of the residuals based on the corresponding OLS estimation results before estimating the parameters of all spatial panel models and common Moran's I index, LM-lag, and LM-err statistics are adapted to discriminate. The results are uniformly reported in Table 2. The Moran's I index and LM-error statistics of each spatial regression equation all pass the significant test at the significance level of $1 \%$, showing that the explanatory variables of each equation have obvious spatial correlation, and also indicating the rationality of using spatial panel model in the empirical analysis.

\section{Empirical Result Analysis}

Table 3 reports the estimated results of Equations (11), (12), and (13). Hausman test results show that it is appropriate to use fixed effects for estimation. Considering the possible estimation deviation of individual differences and period factors, the dynamic spatial panel model is chosen with a two-way fixed effect of time and space to estimate the parameters. For the convenience of comparison, we also report the regression results of the static spatial Durbin model and uses the estimation results of the dynamic spatial Durbin model to analyze.

\section{Analysis of the Impact of Environmental Regulation and Economic Agglomeration on Eco-Efficiency on Eco-Efficiency}

First of all, from the estimated results of model 2 and model 4, we can see that environmental regulation can significantly enhance eco-efficiency. The result is consistent with the findings of $\mathrm{Xu}$ et al. (2021) and Humaira Yasmeen et al. (2020) [21, 42]. The higher the eco-efficiency is, the smaller the comprehensive index of environmental pollution is, and the greater the intensity of environmental regulation is.

As shown in Fig. 2, strengthening environmental regulation will first enable the government to formulate relevant measures. For one thing, the government can directly intervene in the emission behavior, adjust the industrial structure, and promote the integration of regional resources by formulating laws and regulations, shutting down high-polluting enterprises, and other order-controlled environmental regulations. For another

Table 3. Econometric regression results (total sample).

\begin{tabular}{|c|c|c|c|c|c|c|}
\hline \multirow{2}{*}{ Variable } & \multicolumn{2}{|c|}{ Equation (11)/LEE } & \multicolumn{2}{c|}{ Equation (12)/LEE } & \multicolumn{2}{c|}{ Equation (13)/LEA } \\
\cline { 2 - 7 } & $\begin{array}{c}\text { Static (FE) } \\
\text { Model 1 }\end{array}$ & $\begin{array}{c}\text { Dynamic (GMM) } \\
\text { Model 2 }\end{array}$ & $\begin{array}{c}\text { Static (FE) } \\
\text { Model 3 }\end{array}$ & $\begin{array}{c}\text { Dynamic (GMM) } \\
\text { Model 4 }\end{array}$ & $\begin{array}{c}\text { Static (FE) } \\
\text { Model 5 }\end{array}$ & $\begin{array}{c}\text { Dynamic (GMM) } \\
\text { Model 6 }\end{array}$ \\
\hline L.LEE & - & $\begin{array}{c}4.1221^{* * *} \\
(10.97)\end{array}$ & - & $\begin{array}{c}4.1433^{* * *} \\
(9.78)\end{array}$ & - & - \\
\hline L.LEA & - & - & - & - & - & $1.5807^{* * *}$ \\
\hline ER & -0.0345 & $-0.0832^{* *}$ & -0.0409 & $-0.1037^{* *}$ & $-0.5191^{* *}$ & $-0.2593^{*}$ \\
$(2.02)$ & $(1.15)$ & $(2.46)$ & $(2.14)$ & $(1.86)$ \\
\hline
\end{tabular}


Table 3. Continued.

\begin{tabular}{|c|c|c|c|c|c|c|}
\hline$L E A$ & $\begin{array}{c}0.0919^{* * * *} \\
(3.38)\end{array}$ & $\begin{array}{c}0.1255^{* * *} \\
(4.14)\end{array}$ & - & - & - & - \\
\hline SLEA & $\begin{array}{c}0.0490^{* * * *} \\
(3.40)\end{array}$ & $\begin{array}{c}0.0502 * * * \\
(3.16)\end{array}$ & - & - & - & - \\
\hline$C L E A$ & $\begin{array}{c}0.0064^{* * *} \\
(3.20)\end{array}$ & $\begin{array}{c}0.0057 * * * \\
(2.67)\end{array}$ & - & - & - & - \\
\hline$U R$ & $\begin{array}{c}-0.0037 \\
(0.63)\end{array}$ & $\begin{array}{c}-0.0065 \\
(1.10)\end{array}$ & $\begin{array}{c}-0.0054 \\
(0.94)\end{array}$ & $\begin{array}{c}-0.0064 \\
(1.06)\end{array}$ & $\begin{array}{c}0.0478 * * \\
(2.24)\end{array}$ & $\begin{array}{c}0.0322 * * * \\
(2.73)\end{array}$ \\
\hline$S U R$ & $\begin{array}{l}0.0001 \\
(1.30)\end{array}$ & $\begin{array}{c}0.0001^{* *} \\
(2.03)\end{array}$ & $\begin{array}{c}0.0001 \\
(1.55)\end{array}$ & $\begin{array}{c}0.0001 * * \\
(2.37)\end{array}$ & - & - \\
\hline$I S$ & $\begin{array}{c}-0.0031^{*} \\
(1.61)\end{array}$ & $\begin{array}{c}-0.0045^{* *} \\
(2.48)\end{array}$ & $\begin{array}{c}-0.0038^{* *} \\
(2.07)\end{array}$ & $\begin{array}{c}-0.0035 \\
(1.58)\end{array}$ & $\begin{array}{c}-0.0273 * * \\
(2.07)\end{array}$ & $\begin{array}{c}-0.0371 * * * \\
(2.93)\end{array}$ \\
\hline$M A$ & $\begin{array}{c}0.0016 \\
(1.58)\end{array}$ & $\begin{array}{l}0.0008 \\
(0.62)\end{array}$ & $\begin{array}{c}0.0019^{* *} \\
(1.87)\end{array}$ & $\begin{array}{l}0.0008 \\
(0.58)\end{array}$ & $\begin{array}{c}0.0045 \\
(0.68)\end{array}$ & $\begin{array}{l}0.0028 \\
(0.33)\end{array}$ \\
\hline$G R$ & $\begin{array}{c}0.0099 * * * \\
(4.33)\end{array}$ & $\begin{array}{c}0.0161 * * * \\
(5.80)\end{array}$ & $\begin{array}{c}0.0106^{* * *} \\
(4.74)\end{array}$ & $\begin{array}{c}0.0165^{* * *} \\
(6.03)\end{array}$ & $\begin{array}{c}-0.0583 * * * \\
(4.69)\end{array}$ & $\begin{array}{c}-0.0251 * \\
(1.66)\end{array}$ \\
\hline$S T I$ & $\begin{array}{c}0.0696 \\
(1.39)\end{array}$ & $\begin{array}{c}0.0967 * \\
(1.64)\end{array}$ & $\begin{array}{c}0.0679 \\
(1.37)\end{array}$ & $\begin{array}{c}0.1166^{*} \\
(1.93)\end{array}$ & $\begin{array}{c}0.5677 * * \\
(2.55)\end{array}$ & $\begin{array}{c}-0.0771 \\
(0.27)\end{array}$ \\
\hline$F D$ & $\begin{array}{c}-0.1369^{* * *} \\
(3.40)\end{array}$ & $\begin{array}{c}-0.1458^{* * * *} \\
(3.35) \\
\end{array}$ & $\begin{array}{c}-0.1639^{* * *} \\
(4.16) \\
\end{array}$ & $\begin{array}{c}-0.1888^{* * *} \\
(4.33) \\
\end{array}$ & $\begin{array}{c}-0.3646^{* *} \\
(2.39)\end{array}$ & $\begin{array}{c}-0.3894 \\
(1.60) \\
\end{array}$ \\
\hline$T E C$ & $\begin{array}{c}-0.0004 \\
(0.40)\end{array}$ & $\begin{array}{l}0.0008 \\
(0.63)\end{array}$ & $\begin{array}{c}-0.0006 \\
(0.59)\end{array}$ & $\begin{array}{l}0.0006 \\
(0.49)\end{array}$ & $\begin{array}{c}0.0054 \\
(0.89)\end{array}$ & $\begin{array}{l}0.0056 \\
(0.74)\end{array}$ \\
\hline$I F$ & $\begin{array}{c}0.1036 \\
(1.43) \\
\end{array}$ & $\begin{array}{c}-0.0034 \\
(0.04)\end{array}$ & $\begin{array}{c}0.1049 \\
(1.45) \\
\end{array}$ & $\begin{array}{c}-0.0125 \\
(0.15)\end{array}$ & $\begin{array}{c}-0.4316 \\
(1.20)\end{array}$ & $\begin{array}{c}0.0276 \\
(0.06) \\
\end{array}$ \\
\hline$T S A$ & $\begin{array}{c}0.1019 * * \\
(2.22)\end{array}$ & $\begin{array}{c}0.1089 * * \\
(2.00)\end{array}$ & $\begin{array}{c}0.1485^{* * *} \\
(3.36)\end{array}$ & $\begin{array}{c}0.1509^{* * *} \\
(2.86)\end{array}$ & $\begin{array}{c}0.0727 \\
(0.15)\end{array}$ & $\begin{array}{c}0.5721^{* *} \\
(2.04)\end{array}$ \\
\hline$L P$ & $\begin{array}{c}0.4189^{* * *} \\
(6.22)\end{array}$ & $\begin{array}{c}0.3531 * * * \\
(4.53)\end{array}$ & $\begin{array}{c}0.4296^{* * * *} \\
(6.58)\end{array}$ & $\begin{array}{c}0.3422 * * * \\
(4.32)\end{array}$ & $\begin{array}{c}0.0116 \\
(0.02) \\
\end{array}$ & $\begin{array}{c}0.3998 \\
(0.94) \\
\end{array}$ \\
\hline$w^{*} L E E$ & $\begin{array}{c}-0.2617^{* * *} \\
(3.39)\end{array}$ & $\begin{array}{c}-0.0775^{* * *} \\
(2.59)\end{array}$ & $\begin{array}{c}-0.3199 * * * \\
(4.23)\end{array}$ & $\begin{array}{c}-0.1072 * * \\
(3.61)\end{array}$ & - & - \\
\hline$w^{*} E R$ & $\begin{array}{c}0.1308 \\
(1.40)\end{array}$ & $\begin{array}{c}0.0131 \\
(0.57) \\
\end{array}$ & $\begin{array}{c}0.1864 * * * \\
(4.11)\end{array}$ & $\begin{array}{l}0.0311 \\
(1.33) \\
\end{array}$ & $\begin{array}{c}1.9240 * * \\
(2.50)\end{array}$ & $\begin{array}{l}0.1157 \\
(0.98) \\
\end{array}$ \\
\hline$w^{*} L E A$ & $\begin{array}{c}-0.0137 \\
(0.72) \\
\end{array}$ & $\begin{array}{c}-0.0479 * * * \\
(2.96)\end{array}$ & - & - & $\begin{array}{c}0.4769^{* * *} \\
(5.15)\end{array}$ & $\begin{array}{c}0.0375^{* *} \\
(1.93)\end{array}$ \\
\hline$w^{*} L . L E E$ & - & $\begin{array}{c}0.0038 \\
(0.29) \\
\end{array}$ & - & $\begin{array}{c}0.0001 \\
(0.01) \\
\end{array}$ & - & - \\
\hline$w^{*} L . L E A$ & - & - & - & - & - & $\begin{array}{c}-0.0011 \\
(0.08)\end{array}$ \\
\hline$w * X$ & YES & YES & YES & YES & YES & YES \\
\hline Hausman $[\mathrm{p}]$ & $\begin{array}{c}156.52 \\
{[0.000]}\end{array}$ & - & $\begin{array}{c}50.29 \\
{[0.000]}\end{array}$ & - & $\begin{array}{c}10.22 \\
{[0.051]}\end{array}$ & - \\
\hline $\log -\mathrm{L} / \mathrm{F}[\mathrm{p}]$ & 496.9153 & $77.50[0.000]$ & 489.9885 & $114.60[0.000]$ & -274.2786 & $22.22[0.000]$ \\
\hline $\operatorname{AR}(1)[\mathrm{p}]$ & - & $0.848[0.000]$ & - & $0.840[0.000]$ & - & $0.490[0.000]$ \\
\hline $\mathrm{AR}(2)[\mathrm{p}]$ & - & $-0.096[0.234]$ & - & $-0.087[0.283]$ & - & $-0.010[0.856]$ \\
\hline Sargan [p] & - & {$[0.803]$} & - & {$[0.732]$} & - & {$[0.989]$} \\
\hline
\end{tabular}

Note: L.LEE, L.LEA represent time lag of eco-efficiency and economic agglomeration. $\mathrm{w}^{*} \mathrm{LEE}, \mathrm{w} * \mathrm{ER}$ and $\mathrm{w}^{*}$ LEA represent spatial lag terms of eco-efficiency, environmental regulations, and economic agglomeration, respectively. $\mathrm{w}^{*}$ L.LEE and $\mathrm{w} *$ L.LEA represent the space-time lag terms of eco-efficiency and economic agglomeration, respectively. $* * *, * *,{ }^{*}$ represent $1 \%, 5 \%$, and $10 \%$ significance, respectively. The absolute value of $t$ in parentheses, and the $p$ value in square brackets. The static space panel model reports the likelihood function value. The following is the same. 


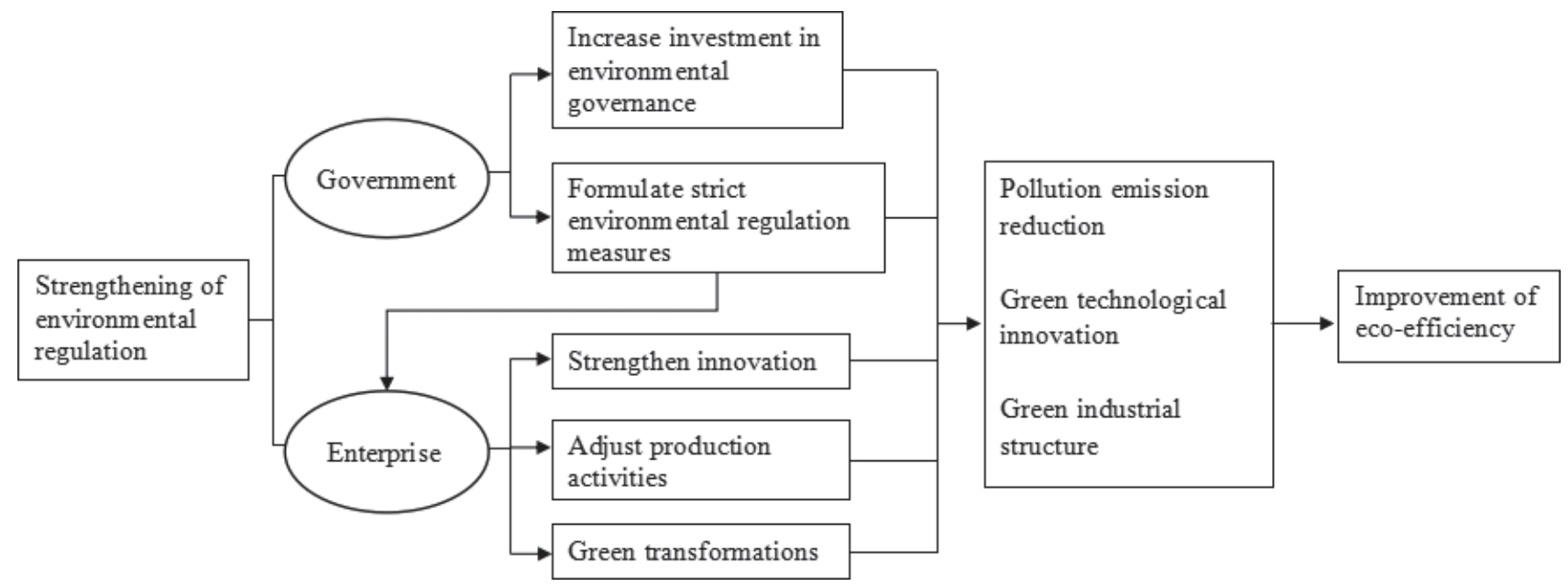

Fig. 2. The mechanism of environmental regulation on eco-efficiency.

thing, the government also uses market tools such as emission rights trading permits, environmental taxes and fees to guide enterprises' emission behavior to promote enterprises to implement green transformation and enhance green technological innovation, thereby benefiting the development of the regional green economy. Second, the strengthening of environmental regulations limits the pollution emission and forces the enterprises to put some production elements into the non-productive activities of reducing pollution emissions such as technology innovation. $\mathrm{Li}$ and Zhao (2021) think that environmental regulation may drive innovation and thus promote growth in green productivity [43]. The burden of enterprises brought about by environmental regulations can be made up by the additional productivity created by green technology innovation brought about by environmental regulations. Besides, under strong environmental regulations, to meet the requirements of the central government on environmental quality, local governments will also devote more resources to environmental protection and pollution treatment, which will enhance eco-efficiency.

Secondly, according to the estimated results of Equation (11), the coefficients of linear, square, and cubic terms of economic agglomeration are all significant at $1 \%$ level, and the cubic term is positive, indicating that a typical $\mathrm{N}$-curve relationship exists between economic agglomeration and eco-efficiency, that is, as the level of economic agglomeration continuously increase, eco-efficiency will show an upward-downward-upward trend. The result is different from (Ren et al. 2019) that concludes that the effect of economic agglomeration on eco-efficiency is linear or inverted U-shaped. Ren et al. (2019) focus on the relationship between industrial agglomeration and green economic efficiency [11], while the economic agglomeration in this paper measures the concentration of regional economic activities as a whole, and the two should be distinguished. Through the calculation of the regression results ${ }^{3}$, we can know that the two extreme points of the "N-shaped" curve are 1.7136 million yuan per sq. $\mathrm{km}$ and 16.4516 million yuan per sq. $\mathrm{km}$.

As shown in Table 4. When the level of economic agglomeration does not exceed 1.7136 million yuan per sq. $\mathrm{km}$, the increase in the level of economic agglomeration can enhance eco-efficiency. In this stage, infrastructure construction is the main task, enterprises in different regions gather less, economies of scale and infrastructure sharing are more conducive to economic output, and pollution emissions have not yet formed a scale. When the level of economic agglomeration rises to more than 1.7136 million yuan per sq. $\mathrm{km}$ less than 16.4516 million yuan per sq. $\mathrm{km}$, it will inhibit ecoefficiency. As the level of agglomeration continues to rise, the economy enters a stage of accelerated development, enterprises gather on a large scale, and industrial enterprises expand rapidly. Meanwhile, because the government is mainly pursuing economic growth, the development of environmental regulations lags behind. At this time, the rate of output expansion caused by economic agglomeration is greater than the rate of environmental input, which leads to largescale pollution emissions and deterioration of the ecological environment, which has a bad effect on ecoefficiency.

When the level of economic agglomeration exceeds 16.4516 million yuan per sq. $\mathrm{km}$, it will enhance eco-efficiency. The environmental problems accumulated in the early stage will urge the government to specify strict environmental regulation, and enterprises will face high emission costs. Meanwhile, the high concentration level also means that the scarcity of relatively fixed land resources will increase, which will increase the expansion cost of enterprises.

\footnotetext{
3 The inflection point values in this paper are obtained by finding the first-order partial derivative of model 2 and making it zero, and then converting the unit.
} 
Table 4. The impact of economic agglomeration on eco-efficiency.

\begin{tabular}{|c|c|c|c|}
\hline $\begin{array}{c}\text { Economic agglomeration level } \\
(\mathrm{EA} / \text { million yuan per sq. } \mathrm{km})\end{array}$ & $\begin{array}{c}\text { Development } \\
\text { stage }\end{array}$ & $\begin{array}{c}\text { Influence } \\
\text { Direction }\end{array}$ & Main transmission mechanism \\
\hline $\mathrm{EA}<1.7136$ & Starting & Positive & $\begin{array}{c}\text { Infrastructure sharing, Cost saving, } \\
\text { Scale economy }\end{array}$ \\
\hline $1.7136<\mathrm{EA}<16.4516$ & Acceleration & Negative & $\begin{array}{c}\text { Expansion of economic scale, Loose environmental } \\
\text { regulations, Heavy industry structure }\end{array}$ \\
\hline $\mathrm{EA}>16.4516$ & Mature & Positive & $\begin{array}{c}\text { Technology spillover, Centralized supervision, Green } \\
\text { transformation }\end{array}$ \\
\hline
\end{tabular}

The productivity reduction caused by the increase of double costs will force enterprises to strengthen technological innovation, promote the rise of regional green economy, and maintain economic growth while reducing pollution emissions. Moreover, under the high level of economic agglomeration, all kinds of positive externalities of agglomeration will be given full play and the government's finance is relatively richer, and more funds can be used for environmental governance.

In 2017, 13 provinces of Beijing, Tianjin, Hebei, Shanxi, Shanghai, Jiangsu, Zhejiang, Anhui, Fujian, Shandong, Henan, Hunan, and Guangdong have exceeded the second threshold point. And continuing to improve the degree of economic agglomeration in these provinces will help to boost their eco-efficiency. In the remaining regions, except Heilongjiang, Qinghai, Ningxia, and Xinjiang, the degree of economic agglomeration only exceeds the first threshold point. At this stage, the level of agglomeration caused by economic development will inevitably continue to increase. If the decline in eco-efficiency is to be suppressed, sound environmental regulations are supposed to be adopted to force enterprises to carry out green technological innovations and reduce pollution.

Last, the results of model 2 show that eco-efficiency has significant time-dependent and spatial-dependent effects. On the one hand, eco-efficiency shows path dependence in the time dimension. If the ecoefficiency of the previous period is at a low level, then the eco-efficiency of the next period may continue to deteriorate. On the other hand, the spatial lag term of eco-efficiency is significantly negative, indicating the geospatial clustering of eco-efficiency is a phenomenon in which regions of high eco-efficiency are encircled by regions of low eco-efficiency. In addition, the spatial lag term of economic agglomeration is also significantly positive, indicating that economic agglomeration in neighboring provinces has a boosting effect on local eco-efficiency. High economic agglomeration and pollution control models in geographically neighboring provinces will form a demonstration effect, and with the strengthening of economic ties, geographically adjacent areas are more likely to form knowledge spillovers so that the economic agglomeration of adjacent areas has a positive correlation with the local eco-efficiency. Nevertheless, the spatial lag of environmental regulation is not significant, showing that it only affects local ecoefficiency. The space-time lag term of eco-efficiency is also not significant.

Besides, from the coefficient estimation of the control variable in the regression result of model 2, the following analysis can be obtained. The quadratic term of the urbanization rate is significantly positive, showing that the relationship between urbanization and eco-efficiency is U-shaped. With the continuous improvement of urban infrastructure and environmental protection consciousness, the externality of economic agglomeration is becoming more and more prominent, which makes the urbanization rate beyond a certain threshold will promote eco-efficiency. The industrial structure is significantly negative, which is consistent with the expectation of this paper. The level of investment in science and technology can facilitate eco-efficiency, and the increase of science and technology investment is beneficial to technological innovation and output in environmental governance. The degree of government intervention is significantly positive, indicating that a certain degree of government intervention is conducive to regulating market failure and promoting the improvement of eco-efficiency.

Fiscal decentralization is significantly negative at $1 \%$ level, indicating that local government competition may make fiscal expenditure biased towards the increase of output while ignoring environmental input, which inhibits the improvement of eco-efficiency. The coefficient of knowledge spillover is positive but not significant, indicating that technological innovation spillover caused by agglomeration may not have a positive effect on eco-efficiency. If technological innovation has the characteristics of "green bias", it will improve eco-efficiency, but if it is oriented to increase productivity, it will lead to the expansion of production scale and will not help reduce pollution emissions. The transport infrastructure is significantly positive, and the improvement of the level of infrastructure can reduce logistics and other costs, making the relationship between enterprises closer, which is conducive to the play of agglomeration externalities and improve ecoefficiency. Finally, the increase in labor productivity can help to improve eco-efficiency. 


\section{Analysis on the Mediating Effect of Economic Agglomeration}

According to the results of model 5 and model 6, the coefficients of environmental regulation in static and dynamic spatial Durbin models are significant at $1 \%$ and $10 \%$, indicating that environmental regulation can enhance economic agglomeration. At the same time, the time lag and spatial lag terms of economic agglomeration are significantly positive, which shows that economic agglomeration also shows the characteristics of path dependence and positive spatial spillover effects.

Economic agglomeration has a significant mediating effect on the impact of environmental regulation on eco-efficiency, which can be analyzed according to the regression results of Equations (11), (12), and (13). The coefficient estimates of the core independent variables in model 2 , model 4 , and model 6 in table 3 have passed the significance test so it can be judged that a partial mediating effect lies in economic agglomeration.
Firstly, the strong environmental regulation will force high-pollution and weak companies to withdraw from the market, which can make the industry's resources more concentrated for green transformation. Secondly, the strengthening of environmental regulations will raise the emission standards of enterprises. At this time, companies can share pollution control facilities through agglomeration to share pollution control costs [23]. And agglomeration is conducive to improving the production efficiency of factors through technology spillovers and other channels. Thereby may cause the double scale effect of controlling pollution and increasing output, which can contribute to the improvement of eco-efficiency. Therefore, while promoting economic agglomeration, environmental regulation can also affect eco-efficiency through agglomeration. This transmission mechanism has not been concerned by the previous literature. Environmental regulation can enhance economic agglomeration, and when the level of economic agglomeration continues to rise above a certain threshold, it will promote eco-efficiency.

Table 5. Robustness test.

\begin{tabular}{|c|c|c|c|}
\hline \multirow{2}{*}{ Variable } & Equation (11)/LEE & Equation (12)/LEE & Equation (13)/LEA \\
\hline & Dynamic (GMM) & Dynamic (GMM) & Dynamic (GMM) \\
\hline L.LEE & $\begin{array}{c}2.7213^{* * *} \\
(15.63)\end{array}$ & $\begin{array}{c}2.2193^{* * *} * \\
(12.08)\end{array}$ & - \\
\hline L.LEA & - & - & $\begin{array}{c}1.8522 * * * \\
(7.74)\end{array}$ \\
\hline$E R$ & $\begin{array}{c}-0.0954 * * \\
(2.08)\end{array}$ & $\begin{array}{c}-0.0892 * * \\
(1.95)\end{array}$ & $\begin{array}{c}-0.6724 * * * \\
(2.80)\end{array}$ \\
\hline$L E A$ & $\begin{array}{c}0.1298^{* * *} \\
(3.95)\end{array}$ & - & - \\
\hline SLEA & $\begin{array}{c}0.0628 * * * \\
(3.40)\end{array}$ & - & - \\
\hline CLEA & $\begin{array}{c}0.0072 * * * \\
(2.95)\end{array}$ & - & - \\
\hline$X$ & YES & YES & YES \\
\hline$w * L E E$ & $\begin{array}{c}0.5329 * * * \\
(4.53)\end{array}$ & $\begin{array}{c}0.5324 * * * \\
(4.34)\end{array}$ & - \\
\hline$w^{*} E R$ & $\begin{array}{l}0.1257 \\
(1.49)\end{array}$ & $\begin{array}{l}0.1081 \\
(1.24)\end{array}$ & $\begin{array}{l}0.0594 \\
(0.81)\end{array}$ \\
\hline$w^{*} L E A$ & $\begin{array}{c}-0.0010 \\
(0.01)\end{array}$ & - & $\begin{array}{c}0.1997 * * * \\
(5.20)\end{array}$ \\
\hline$w^{*} L . L E E$ & $\begin{array}{c}-0.0014 \\
(0.24)\end{array}$ & $\begin{array}{c}-0.0028 \\
(0.35)\end{array}$ & - \\
\hline$w^{*} L . L E A$ & - & - & $\begin{array}{c}-0.0028 \\
(0.55)\end{array}$ \\
\hline$w^{*} X$ & YES & YES & YES \\
\hline $\mathrm{F}(\mathrm{P})$ & $11.3649[0.000]$ & $11.0044[0.000]$ & $22.9673[0.000]$ \\
\hline $\operatorname{AR}(1)[\mathrm{p}]$ & $0.875[0.000]$ & $0.771[0.000]$ & $0.209[0.000]$ \\
\hline $\operatorname{AR}(2)[\mathrm{p}]$ & $-0.738[0.278]$ & $-0.033[0.616]$ & $-0.046[0.268]$ \\
\hline Sargan $[\mathrm{p}]$ & [0.899] & {$[0.843]$} & {$[0.892]$} \\
\hline
\end{tabular}


The joint implementation of environmental regulation and economic agglomeration policy will help to achieve green development.

\section{Robustness Test}

In two regions with similar levels of economic agglomeration, the corresponding industrial economic behaviors and the agglomeration and allocation methods of factors will also tend to be the same, which makes the links between regions with similar levels of economic agglomeration closer. Based on this realistic background, this paper constructs a spatial weight matrix $W_{i j}{ }^{2}$ based on the distance of economic agglomeration, and re-estimates the models (11), (12), and (13) to verify the robustness of the previous regression results. The calculation process of $W_{i j}{ }^{2}$ is as follows:

$$
W_{i j}^{2}=\frac{1}{\left[1+a b s\left(R_{i}-R_{j}\right)\right]}
$$

where $R_{i}$ is the average economic agglomeration level of region $i$ from 2003 to 2017, and its calculation formula is:

$$
R_{i}=\frac{X_{i} / \sum_{i=1}^{N} X_{i}}{T E R_{i} / \sum_{i=1}^{N} T E R_{i}}
$$

where $X_{i}$ is the non-agricultural output of region $i, T E R_{i}$ is the built-up area of region $i$, and $\mathrm{N}$ is the number of regions.

Table 5 reports the estimated results of the robustness test. From the estimated results of Equation (11), we can see that the coefficient symbols of the linear, square and cubic terms of economic agglomeration are consistent with the result of model 2 in Table 3, and have passed the significance test. It shows that an N-curve relationship exists between economic agglomeration and eco-efficiency. The core explanatory variables in the estimated results of (11), (12), and (13) all pass the significance test, and the symbol of the coefficient is consistent with Table 3, which once again verifies that the partial mediating effect of economic agglomeration is valid. The above shows the robustness of the previous conclusions.

It is worth noting that the coefficient of the spatial lag of eco-efficiency is significantly positive under the setting of economic agglomeration distance spatial weight matrix, which indicates that the spillover effect of regional ecological efficiency in China is positive among regions with a similar level of economic agglomeration. Regions with similar levels of economic agglomeration have closer industrial structures and resource allocation methods, and the corresponding green development methods and pollution treatment models will form a strong demonstration effect and promote eco-efficiency. Economic agglomeration still has a positive spatial correlation under the setting of economic distance spatial weight matrix.

\section{Regional Heterogeneity Analysis}

China has a vast territory, and there are some differences in resource endowment, natural environment, and economic development level in different regions. Based on the robustness of the previous conclusion, in order to compare whether there are differences in the impact of environmental regulations and economic agglomeration on ecoefficiency among different regions, the sample is divided into eastern, central, and western regions, and the spatial weight matrix of economic agglomeration distance is used to re-estimate the Equation (11). The specific empirical results are shown in Table 6.

Firstly, the coefficient symbols of environmental regulation in the three regions are consistent with the empirical results of the whole sample and pass the significance test, which shows that environmental regulation has a significant promoting effect on ecoefficiency. From the estimated results of the coefficient, the role of environmental regulation in promoting ecoefficiency in the central and western regions is stronger than that in the eastern region. This may be caused by the differences in the degree of economic agglomeration between regions, and there will be differences in industrial structure, technological innovation, and resource allocation among regions with different degrees of economic agglomeration. The eastern region of China, with a high level of economic agglomeration, has always been the forerunner of China's reform, opening up, and economic development. Its industrial diversification and industrial structure transformation and upgrading process are relatively fast. In the eastern region, from enterprise start-up to environmental supervision and other aspects of policy and pollution treatment and other infrastructure are relatively perfect, its level of environmental regulations is high, and pollution emissions have been maintained at a relatively low level. Thus, the continuous improvement of the level of environmental regulation on the promotion of eco-efficiency may have a diminishing effect of marginal utility.

Secondly, the coefficient test results of the linear, square, and cubic terms of economic agglomeration in the central region are all significant and the symbols are consistent with the results of the whole sample test. The coefficients of linear, square, and cubic terms of economic agglomeration in the eastern region have also passed the significance test, but the coefficient of the cubic term is negative, indicating that economic agglomeration and eco-efficiency present an "inverted N-type" curve relationship in the eastern region. Through the calculation of the extreme point of the "inverted N-type", it is found that the economic 
Table 6. Regional heterogeneity test.

\begin{tabular}{|c|c|c|c|}
\hline \multirow{2}{*}{ Variable } & Eastern & Central & Western \\
\hline & Dynamic (GMM) & Dynamic (GMM) & Dynamic (GMM) \\
\hline L.LEE & $\begin{array}{c}4.7425^{* * *} \\
(10.85)\end{array}$ & $\begin{array}{c}1.6659 * * * \\
(16.71)\end{array}$ & $\begin{array}{c}2.8304^{* * *} \\
(14.78)\end{array}$ \\
\hline ER & $\begin{array}{c}-0.0071^{* *} \\
(2.16)\end{array}$ & $\begin{array}{c}-0.3606^{* *} \\
(2.38)\end{array}$ & $\begin{array}{c}-0.1063^{* *} \\
(2.31)\end{array}$ \\
\hline LEA & $\begin{array}{c}0.3806^{* * *} \\
(4.01)\end{array}$ & $\begin{array}{c}0.2473^{* * *} * \\
(3.49)\end{array}$ & $\begin{array}{c}0.0302 \\
(0.64)\end{array}$ \\
\hline SLEA & $\begin{array}{c}0.3670 \text { *** } \\
(4.97)\end{array}$ & $\begin{array}{c}0.1157 * * \\
(2.58)\end{array}$ & $\begin{array}{c}0.0139 \\
(0.59)\end{array}$ \\
\hline CLEA & $\begin{array}{c}-0.0758^{* * *} \\
(5.17)\end{array}$ & $\begin{array}{c}0.0162 * * \\
(1.88)\end{array}$ & $\begin{array}{l}0.0016 \\
(0.58)\end{array}$ \\
\hline $\mathrm{X}$ & YES & YES & YES \\
\hline $\mathrm{w}^{*}$ LEE & $\begin{array}{c}1.2662 * * * \\
(7.90)\end{array}$ & $\begin{array}{c}0.6313^{* * *} \\
(2.82)\end{array}$ & $\begin{array}{c}0.5667 * * * \\
(2.82)\end{array}$ \\
\hline $\mathrm{w} * \mathrm{ER}$ & $\begin{array}{c}-0.0593 \\
(0.19)\end{array}$ & $\begin{array}{c}-0.1712 \\
(0.73)\end{array}$ & $\begin{array}{c}0.1172 * * \\
(2.23)\end{array}$ \\
\hline $\mathrm{w}^{*}$ LEA & $\begin{array}{c}0.5508 * * \\
(2.00)\end{array}$ & $\begin{array}{l}0.0780 \\
(0.33)\end{array}$ & $\begin{array}{c}-0.0251 \\
(0.19\end{array}$ \\
\hline $\mathrm{w}^{*}$ L.LEE & $\begin{array}{c}0.0649 * * * \\
(3.91)\end{array}$ & $\begin{array}{c}-0.0676 \\
(1.36)\end{array}$ & $\begin{array}{c}-0.0667 \\
(1.48)\end{array}$ \\
\hline $\mathrm{w}^{*} \mathrm{X}$ & YES & YES & YES \\
\hline $\mathrm{F}(\mathrm{P})$ & $15.3930[0.000]$ & $14.8511[0.000]$ & $2.06[0.003]$ \\
\hline $\operatorname{AR}(1)[\mathrm{p}]$ & $0.8739[0.000]$ & $0.6676[0.000]$ & $1.0266[0.000]$ \\
\hline $\operatorname{AR}(2)[\mathrm{p}]$ & $-0.0726[0.709]$ & $-0.0803[0.485]$ & $-0.0296[0.676]$ \\
\hline Sargan $[\mathrm{p}]$ & [0.999] & {$[0.713]$} & {$[0.840]$} \\
\hline
\end{tabular}

agglomeration level of the second extreme point is 2.0004 billion yuan per sq. km. However, Shanghai, which has the highest economic agglomeration in the eastern region, has a value of only 195.7914 million yuan per square kilometer in 2017, far less than the second extreme point. Therefore, at the present stage, the improvement of the level of economic agglomeration in the eastern region mainly promotes eco-efficiency. The coefficients of the linear, square, and cubic terms of economic agglomeration in the western region are not significant, but the coefficient signs are consistent with the whole sample. This may be because the western region is mostly sparsely populated and economic development is relatively backward. The overall degree of economic agglomeration and the scale effect have not reached a high level, so its time series are not significantly related to eco-efficiency.

\section{Conclusions and Policy Implications}

This paper explores the impact of environmental regulation and economic agglomeration on regional ecological efficiency in China. Furthermore, whether the effective improvement of eco-efficiency can have a reactionary force on environmental regulations and economic agglomeration requires further analysis in future research. The main conclusions of this paper are as follows.

Firstly, from 2003 to 2007, the eco-efficiency at the total sample level showed a downward trend and then tended to be stable, indicating that the policy effect of China's green development is gradually playing a role. And the differences of inter-regional eco-efficiency in China are that the eco-efficiency of eastern regions was far ahead of the national average level and inland areas, and the central region is the lowest.

Secondly, from the perspective of temporal evolution characteristics, environmental regulation can not only directly promote the improvement of ecoefficiency, but also indirectly affect eco-efficiency by affecting economic agglomeration. A typical "N-type" curve relation exists between economic agglomeration and eco-efficiency. With the increase of the industrial proportion and overutilization of resources and the environment, when the agglomeration reaches a certain threshold, the eco-efficiency will be adversely affected. At this stage, the positive function of environmental regulation on economic agglomeration can be exerted to promote green economic agglomeration and 
form a virtuous circle. When the level of economic agglomeration continues to rise above a certain threshold, it will promote eco-efficiency. In 2017, only the economic agglomeration level of 13 provincial regions, such as Beijing and Tianjin, exceeded the second threshold point, which can enhance ecoefficiency. However, the economic agglomeration level of most central and western provincial regions only exceeded the first threshold point, In the future, these regions can improve eco-efficiency through the coordination of environmental regulations and agglomeration economies.

Thirdly, both eco-efficiency and economic agglomeration have significant time dependence and spatial spillover effects. In the time dimension, if the eco-efficiency and economic agglomeration in the previous period were at a relatively high level, the eco-efficiency and economic agglomeration in the next period may also continue to rise. In the spatial dimension, eco-efficiency shows significant negative spatial correlation under the setting of geographical adjacency spatial weight matrix, while positive spatial correlation under the setting of economic agglomeration distance spatial weight matrix. Economic agglomeration shows positive spatial correlation under the setting of two kinds of spatial weight matrices. Besides, the improvement of the agglomeration level in the adjacent areas can promote local eco-efficiency.

Finally, judging from the characteristics of spatial differentiation, the environmental regulation in the eastern, central, and western regions all play a significant role in promoting eco-efficiency. From the estimated results of the coefficients, the effect of environmental regulation on eco-efficiency in the central and western regions is stronger than that in the eastern regions. This further shows that the continuous improvement of the level of environmental regulation may have a diminishing marginal utility effect on ecological efficiency. The effect of economic agglomeration on eco-efficiency shows significant $\mathrm{N}$-type characteristics in the central region, which is consistent with the whole sample. In the eastern region, it shows the inverted N-type, but at the present stage, the increase of the degree of economic agglomeration in the eastern region mainly promotes eco-efficiency.

According to the above conclusions, policy implications are as follows:

First, the current level of economic agglomeration in some developed provinces in China has crossed the critical point where economic agglomeration promotes ecological efficiency. With the continuous improvement of China's regional economic agglomeration level, it can be expected that its promotion of eco-efficiency will be realized on a larger scale. Therefore, China should continue to develop the economy of urban agglomerations, promote regional economic integration, break down inter-regional trade barriers, strive to enhance the degree of economic agglomeration in various regions so that it can improve eco-efficiency.
Second, although problems such as high pollution emissions caused by agglomeration are more prominent, it also shows that economic agglomeration is still at a low level. Environmental regulations can promote green technology innovation and industrial upgrading transformation, so as to promote green economy agglomeration. Therefore, the government is supposed to enhance the order-controlled environmental regulations, perfect the market incentive environmental regulations, improve environmental legislation and supervision, and jointly promote the development of the green economy.

Third, both eco-efficiency and economic agglomeration have significant spatial spillover effects, which indicates that the green economy can be effectively realized by promoting the coordination and linkage mechanism of inter-regional environmental regulation policies. The provinces in eastern China should play the "demonstration effect" of high eco-efficiency areas and strengthen the help to the green innovation technology in the central and western regions.

\section{Acknowledgment}

This work was funded by the Social Science Foundation of Liaoning Province, grant number L18BJL011. The authors are grateful to the reviewers and editors for their profound opinions and suggestions. The authors would also like to thank Minghao Zhang and Minglang Zhang for their participation in literature collation and data collation.

\section{Conflict of Interest}

The authors declare no conflict of interest.

\section{References}

1. WU D., WANG Y., QIAN W. Efficiency evaluation and dynamic evolution of China's regional green economy: A method based on the Super-PEBM model and DEA window analysis. J. Clean. Prod. 264, 121630, 2020.

2. SHAO S., ZHANG K., DOU J. Effects of economic agglomeration on energy saving and emission reduction: theory and empirical evidence from China. Manage World. 35, 36, 2019 [In Chinese].

3. ZHOU Y., KONG Y., ZHANG T. The spatial and temporal evolution of provincial eco-efficiency in China based on SBM modified three-stage data envelopment analysis. Environ. Sci. Pollut. Res. 27, 8557, 2020.

4. SU K., CHEN Y. An Empirical Study on Ecological Efficiency and Influencing Factors of Industrial Enterprises in Fujian Province, China. Pol. J. Environ. Stud. 28(6), 4381, 2019.

5. SCHALTEGGER S., STURM A. Ökologische rationalität: ansatzpunkte zur ausgestaltung von ökologieorientierten managementinstrumenten. Die Unternehmung. 44, 273, 1990. 
6. UNCTAD. A manual for the preparers and users of ecoefficiency indicators. United Nations Conference on Trade and Development, Geneva: UNCTAD. 2003.

7. PORTER M.E. On Competition. Harvard Business School Press, Boston, 1998.

8. LIU S., ZHU Y., DU K. The impact of industrial agglomeration onindustrial pollutant emission: evidence from China under new nor-mal. Clean Technol. Environ. Policy 19, 2327, 2017.

9. ZHANG K., XU D., LI S. The impact of environmental regulation on environmental pollution in China: an empirical study based on the synergistic effect of industrial agglomeration. Environ. Sci. Pollut. Res. 26, 25775, 2019.

10. LIU J., CHENG Z., ZHANG H. Does industrial agglomeration promote the increase of energy efficiency in China? J. Clean. Prod. 164, 30, 2017.

11. ZHU Y., XIA Y. Industrial agglomeration and environmental pollution: Evidence from China under New Urbanization. Energy Environ. 30, 1010, 2019.

12. LI H., XU Y., YAO X. Effects of industrial agglomeration on haze pollution: A Chinese city-level study. Energy Policy. 148, 111928, 2021.

13. REN Y., WANG C., XU L. et al. Spatial spillover effect of producer services agglomeration on green economic efficiency: empirical research based on spatial econometric model. J. Intell. Fuzzy Syst. 37, 6389, 2019.

14. YU Y., ZHANG Y., MIAO X. Impacts of Dynamic Agglomeration Externalities on Eco-Efficiency: Empirical Evidence from China. Int. J. Environ. Res. Public Health 15, 2018.

15. LIN B., TAN R. Economic Agglomeration and Green Economy Efficiency in China. Econ. Res. J. 54, 119, 2019 [In Chinese].

16. LI B., WU S. Effects of local and civil environmental regulation on green total factor productivity in China: a spatial Durbin econometric analysis. J. Clean. Prod. 153, 342, 2017.

17. LI X., WANG Y., LI C. Evolution of Environmental Regulation Strategy among Local Governments and Its Impact on Regional Ecological Efficiency in China. Environ. Eng. Manag. J. 16 (10), 2425, 2017.

18. SUN Y., DU J., WANG S. Environmental regulations, enterprise productivity, and green technological progress: large-scale data analysis in China. Ann. Oper. Res. 290, 369, 2020.

19. PORTER M.E., VANDERLINDE C. Toward a New Conception of the Environment-Competitiveness Relationship. J. Econ. Perspect. 9, 97, 1995.

20. RUBASHKINA Y., GALEOTTI M., VERDOLINI E. Environmental regulation and competitiveness: empirical evidence on the Porter hypothesis from European manufacturing sectors. Energy Policy. 83, 288, 2015.

21. XU X., CUI Y., ZHONG Y. Impact of Environmental Regulation and FDI on Green Total Factor Productivity: Evidence from China. Environ. Eng. Manag. J. 20 (2), 177, 2021.

22. XIE R., YUAN Y., HUANG J. Different Types of Environmental Regulations and Heterogeneous Influence on "Green" Productivity: Evidence from China. Ecol. Econ. 132, 104, 2016

23. LUO N., WANG Y. Fiscal decentralization, environmental regulation and regional eco-efficiency: based on the dynamic spatial Durbin model. China Popul. Resour. Environ. 27, 110, 2017 [In Chinese].

24. SHEN N., LIAO H., DENG R., WANG Q. Different types of environmental regulations and the heterogeneous influence on the environmental total factor productivity: Empirical analysis of China's industry. J. Clean. Prod. 211, 171, 2019.

25. KONG H., YU Q., ZHANG X. Environmental Regulation, Economic Agglomeration and Urban Productivity. Inquiry. Econ. Issues. 438, 79, 2019 [In Chinese].

26. ANDREONI J., LEVINSON A. The simple analytics of the environmental Kuznets curve. J. Public Econ. 80, 269, 2001.

27. WANG Y., YAN W., MA D. Carbon emissions and optimal scale of China's manufacturing agglomeration under heterogeneous environmental regulation. J. Clean. Prod. 176, 140, 2018.

28. HAO S., ZHANG Y. The Impact of Environmental Regulation on Economic Agglomeration: from the Perspective of New Economic Geography. Soft. Sci. 30, 27, 2016.

29. CICCONE A., HALL R.E. Productivity and the density of economic activity. Am. Econ. Rev. 86, 54, 1996.

30. USHIFUSA Y., TOMOHARA A. Productivity and Labor Density: Agglomeration Effects over Time. Atl. Econ. J. 41, 123, 2013.

31. FISHER-VANDEN K., JEFFERSON G.H., LIU H., TAO Q. What is driving China's decline in energy intensity? Resour. Energy Econ. 26, 2287, 2004.

32. CHUNG Y.H., FARE R., GROSSKOPF S. Productivity and undesirable outputs: A directional distance function approach. J. Environ. Manage. 51, 229, 1997.

33. GONG Y., ZHU J., CHEN Y., COOK W.D. DEA as a tool for auditing: application to Chinese manufacturing industry with parallel network structures. Ann. Oper. Res. 263, 247, 2018.

34. TONE K. A slacks-based measure of super-efficiency in data envelopment analysis. Eur. J. Oper. Res. 143, 32, 2002.

35. MA X., LI Y., ZHANG X., WANG C., et al. Research on the ecological efficiency of the Yangtze River Delta region in China from the perspective of sustainable development of the economy-energy-environment (3E) system. Environ. Sci. Pollut. Res. 25, 29192, 2018.

36. SHAN H. Reestimating the Capital Stock of China: 1952 2006. J. Quant. Tech. Econ. 143, 32, 2008.

37. CHEN H., DONG K., WANG F., EMMANUEL C.A. The spatial effect of tourism economic development on regional ecological efficiency. Environ. Sci. Pollut. Res. 27 (30), 38241, 2020.

38. YU Y., HU H., ZHANG Y., YIN Z. Metafrontier EcoEfficiency and Its Convergence Analysis for China: A Multidimensional Heterogeneity Perspective. Emerg. Mark. Financ. Trade. 55, 1531, 2019.

39. ELHORST J.P. Spatial Econometrics: From Crosssectional Data to Spatial Panels. Springer, New York, 2014.

40. BARON R.M., KENNY D.A. The Moderator-Mediator Variable Distinction in Social Psychological Research. J. Pers. Soc. Psychol. 51, 1173, 1986.

41. HAN C, PHILLIPS P.C.B. GMM Estimation for Dynamic Panels with Fixed Effects and Strong Instruments at Unity. Economet. Theory. 26, 119, 2010.

42. HUMAIRA Y., TAN Q, ZAMEER H., TAN J., NAWAZ $\mathrm{K}$. Exploring the impact of technological innovation, environmental regulations and urbanization on ecological efficiency of China in the context of COP21. J. Environ. Manage. 274, 111210, 2020.

43. LI D., ZHAO Y. How does Environmental Regulation Effect Green Growth? An Empirical Investigation from China. Pol. J. Environ. Stud. 30 (2), 1247, 2021. 